\title{
Períodos de estratificação e concentrações de giberelina na emergência de plântulas de porta-enxertos de pessegueiro
}

\author{
Stratification periods and gibberellin concentration on the emerged \\ seedlings of peach rootstocks
}

\author{
Antonio Sidnei Martins ${ }^{1 * *}$ \\ Valmor João Bianchi ${ }^{2}$ \\ Moacir da Silva Rocha ${ }^{3}$ \\ José Carlos Fachinello ${ }^{4}$
}

\section{Resumo}

No Brasil a produção de porta-enxertos de pessegueiro é feita principalmente por sementes, as quais apresentam grau de dormência variável entre cultivares, que pode ser limitante para a emergência e crescimento dos seedlings. Dentre as estratégias para obter melhores taxas de germinação e estabelecimento das plântulas está à estratificação em baixa temperatura e o tratamento das sementes com fitorreguladores. Sendo assim, o presente trabalho objetivou verificar como a estratificação e aplicação de giberelina influencia na emergência e no desenvolvimento das plântulas. Sementes dos porta-enxertos de pessegueiro Nemaguard e Seleção 039.03.02 foram submetidas à estratificação ( 0,15 e 30 dias), a $1^{\circ} \mathrm{C}$, e a concentração de giberelina $\left(0,50\right.$ e $\left.100 \mathrm{mg} \mathrm{L}^{-1}\right)$. As variáveis analisadas foram: índice de velocidade de emergência a campo (IVEC), percentagem de plântulas emergidas e de plântulas com sintomas de nanismo fisiológico, diâmetro do tronco e altura de plantas. Observou-se que a estratificação a $1^{\circ} \mathrm{C}$ por 30 dias, permitiu antecipar e homogeneizar o início da emergência e obter maiores percentuais de plântulas emergidas para ambas cultivares. $\mathrm{O}$ uso de giberelina na concentração de $100 \mathrm{mg} \mathrm{L}^{-1}$ possibilitou obter maior percentual de plântulas emergidas, porém, mesmo associado à estratificação em frio, não eliminou completamente os sintomas de nanismo fisiológico. Devido às melhores taxas

I MSc.; Engenheiro Agrônomo; Assistente Técnico a fruticultores em seus plantios comerciais de frutas de caroço, Prefeitura Municipal de Irati; Endereço: Rua Cel. Emilio Gomes, 22, CEP: 84500-000, Irati, Paraná, Brasil; E-mail: toninho@irati.pr.gov.br $\left(^{*}\right)$ Autor para correspondência.

2 Dr.; Engenheiro Agrônomo; Professor do Departamento de Botânica, Programas de Pós-Graduação em Fisiologia Vegetal e em Agronomia da Universidade Federal de Pelotas, UFPel; Pelotas, Rio Grande do Sul, Brasil; Bolsista de Produtividade em Pesquisa do CNPq; E-mail: valmorjb@yahoo.com

3 Dr.; Engenheiro Agrônomo; Professor da Universidade Federal de Pelotas, UFPel; Pelotas, Rio Grande do Sul, Brasil; E-mail: moacirrocha@brturbo.com.br

4 Pós-Doutorado; Engenheiro Agrônomo; Professor do Departamento de Fitotecnia, Programa de PósGraduação em Agronomia da Universidade Federal de Pelotas, UFPel; Pelotas, Rio Grande do Sul, Brasil; Bolsista de Produtividade em Pesquisa do CNPq; E-mail: jfachi@ufpel.tche.br

Recebido para publicação em 10/07/2009 e aceito em 27/09/201 I

\begin{tabular}{llllll}
\hline Ambiência Guarapuava (PR) & v.7 n.3 & p. 50I-5I4 & Set./Dez. 20II & ISSN I808 - 025I
\end{tabular}

DOI:10.5777/ambiencia. 201 I.03.08 
de emergência, IVEC e menor taxa de nanismo fisiológico, verificou-se que as sementes de Seleção 039.03-02 respondem mais aos tratamentos de estratificação, apresentando melhores resultados para uso na propagação, em relação à cv. Nemaguard.

Palavras-chave: Prunus sp.; propagação por sementes; tratamento térmico; fitorreguladores.

\section{Abstract}

In Brazil, peach rootstocks production is made mainly by seeds, which has variable dormancy degree among cultivars and it can be a limiting factor for emergency and seedlings growth. Strategies for obtaining better rates of germination and plant development include the stratification at low temperatures and the seeds treatment with plant growth regulators. Thus, the present work aimed at verifying how the stratification and the gibberellin concentrations influence emergency and seedlings development. Seeds from peach rootstocks Nemaguard and Seleção 039.03.02 were submitted at different periods of stratification $\left(0,15\right.$ and 30 days), at $1^{\circ} \mathrm{C}\left( \pm 1^{\circ} \mathrm{C}\right)$, and gibberellin concentration $(0,50$ and $100 \mathrm{mg} \mathrm{L}-1)$. The variables analyzed were: index emergence speed at field (IESF), percentage of emerged seedlings and percentage of seedlings with physiologic dwarf symptoms, trunk diameter and plants height. It was observed that stratification at $1^{\circ} \mathrm{C}$ per 30 days allowed to anticipate the seedlings emergence and to obtain larger percentage of emerged seedlings for both cultivars. The gibberellin used at $100 \mathrm{mg} \mathrm{L}-1$ concentration allowed to obtain larger percentage of emerged seedlings, however, even associated to the stratification, it wasn't efficient to eliminate completely the physiologic dwarf symptoms. Due the better percentage of emergence, IESF and smaller percentage of physiologic dwarf symptoms, it was suggested that seeds from Seleção 039.03.02 respond better to stratification, than those of Nemaguard cultivar.

Key words: Prunus sp.; propagation by seeds; thermal treatment; plant growth regulators.

\section{Introdução}

O pessegueiro [Prunus persica (L.) Batsch] é a principal frutífera de caroço cultivada no Brasil e a obtenção de suas mudas é uma importante etapa da cadeia produtiva desta espécie (SOUZA et al., 2002). Nesse contexto, o porta-enxerto tem uma relevância inquestionável, uma vez que é a parte responsável pela ancoragem, absorção de água e nutrientes, armazenamento de reservas, biosíntese de fitohormônios, estando em contado com os agentes bióticos e abióticos do solo, além de influenciar em várias características da cultivar copa.

No Brasil, desde a década de 1940, a produção comercial de mudas de pessegueiro é feita principalmente por enxertia das cultivares copa sobre porta-enxertos obtidos de sementes (FINARDI, 1998). Entretanto, as pesquisas com porta-enxertos de Prunus ainda são incipientes quanto ao 
melhoramento genético para obtenção de novos genótipos, bem como sobre os fatores que podem influenciar na propagação dos diferentes porta-enxertos.

Muito embora na propagação sexuada possa não ocorrer a manutenção de todas as características da planta matriz, na obtenção de porta-enxertos de pessegueiro via sementes tem sido observado que uma característica importante, a resistência aos nematóides das galhas (Meloidogyne spp.), é transmitida aos seedlings por cultivares como Okinawa, Nemaguard, Floradaguard e Tsukuba, bem como aos híbridos envolvendo tais genótipos (FACHINELLO,2000; PAULA et al.,2009). Entretanto, a viabilidade e a taxa de germinação das sementes dos diferentes genótipos de Prunus pode variar muito (RAMOS et al., 2002), necessitando-se testar que fatores podem influenciar positivamente na germinação, emergência e no crescimento das plântulas.

Dentre os fatores que limitam a germinação das sementes de pessegueiro está a dormência e a resistência física exercida pelo endocarpo. A presença e o equilíbrio dos fitohormônios, atuando como promotores e inibidores de crescimento têm papel fundamental na germinação. As giberelinas, as citocininas e o etileno promovem a germinação, enquanto que o ácido abscísico induz à dormência (CASTRO; VIEIRA, 2001). As giberelinas influenciam a germinação por atuarem na regulação da síntese de enzimas envolvidas na mobilização das reservas energéticas dos cotilédones da semente para o embrião estimulando a germinação (TAIZ; ZEIGER, 2009). Picolloto et al. (2007a) demostraram que sementes de porta-enxertos de pessegueiro de diferentes cultivares apresentam respostas diferenciadas na germinação quando tratadas com giberelinas ou pelo uso combinado de giberelinas e citocinina.
Alguns estudos têm demonstrado que a temperatura interage diretamente com os fitohormônios, alterando seus níveis endógenos e, por conseqüência, influenciando na regulação do processo germinativo, induzindo a germinação de sementes em diversas espécies (CASTRO; VIEIRA, 2001). Quando não submetidas a tratamentos para a superação da dormência, sementes de portaenxertos de pessegueiro podem ter baixa taxa de germinação, e as plântulas resultantes muitas vezes apresentam-se anormais, com sintomas de nanismo fisiológico e baixo crescimento vegetativo, resultando em plantas desuniformes e com baixa qualidade para uso como porta-enxerto (BARBOSA et al.,1987).

A estratificação de sementes de pessegueiro em ambiente úmido com baixa temperatura $\left(5-10^{\circ} \mathrm{C}\right)$ constante ou alternada (BARBOSA et al., 1986), associada ou não ao uso de substâncias reguladoras do crescimento (AZEVEDO et al., 2004), torna-se indispensável quanto se deseja obter lotes de seedlings de porta-enxertos uniformes.

Considerando que diferentes genótipos de pessegueiro possuem variabilidade no grau de dormência das suas sementes e podem responder diferencialmente aos fatores do meio que induzem a germinação, o presente trabalho objetivou verificar se a estratificação e aplicação de giberelina influencia de forma diferenciada a emergência e o crescimento das plântulas dos porta-enxertos de pessegueiro Seleção 039.03-02 e Nemaguard.

\section{Material e Métodos}

O experimento foi conduzido nas dependências do Departamento de Fitotecnia da Faculdade de Agronomia Eliseu Maciel (FAEM), Universidade Federal de Pelotas (UFPel), Pelotas-RS. 
Caroços dos porta-enxertos de pessegueiro [Prunus persica (L.) Batsch] Seleção 039.03-02 (seleção obtida da livre polinização da cultivar Capdeboscq) e da cultivar Nemaguard, colhidos em dezembro de 2003 e fevereiro de 2004, respectivamente, foram obtidos no Banco de Germoplasma do Centro Agropecuário da Palma - UFPel, Capão do Leão-RS.

Após a colheita, os frutos foram despolpados, lavados com água corrente e colocados para secar a sombra. No dia 17 de fevereiro de 2004, os caroços foram flambados com o uso de álcool em uma bandeja metálica. Em cada lote de vinte a trinta caroços foram adicionados cinco $\mathrm{mL}$ de álcool etílico $92,8^{\circ}$ e levemente agitados expondo todas as partes dos caroços à chama, a fim de eliminar patógenos. Em seguida, foi feita a extração das sementes dos caroços, sendo estes quebrados com auxílio de torno manual, desinfestado com álcool a 70\%. Após a imersão em solução de hipoclorito de sódio $(1,5 \%)$ durante um minuto, as sementes foram lavadas em água destilada. Em seguida, foram imersas em soluções contendo diferentes concentrações de giberelina, durante oito horas para posteriormente serem utilizadas nos tratamentos de estratificação. O produto comercial contendo giberelina foi o Pro-gibb ${ }^{\circledR}\left(10 \%\right.$ de $\left.\mathrm{GA}_{3}\right)$.

O delineamento experimental foi inteiramente casualizado, com três repetições de quinze sementes por unidade experimental, segundo um fatorial $2 \times 3 \times 3$, composto pelos fatores: genótipo (Nemaguard e Seleção 039.03-02), período de estratificação $(0,15$ e 30 dias) e concentrações de $\mathrm{GA}_{3}(0,50$ e $\left.100 \mathrm{mg} \mathrm{L}^{-1}\right)$, totalizando dezoito tratamentos.

As sementes dos tratamentos com quinze e trinta dias de estratificação em frio foram acondicionadas em placas de Petri esterilizadas, contendo uma folha de papel filtro, as demais permaneceram em temperatura ambiente. Em cada placa adicionou-se $1 \mathrm{~mL}$ de solução fungicida (200mL de água destilada $+150 \mathrm{mg}$ de Procimidona), sendo em seguida vedadas com parafilme e armazenadas em geladeira, à temperatura controlada $\left(1^{\circ} \mathrm{C} \pm 1^{\circ} \mathrm{C}\right)$.

No dia 18 de fevereiro de 2004, as sementes do tratamento sem frio foram semeadas à profundidade de $1 \mathrm{~cm}$, em substrato composto de casca de pinus e vermiculita (Plantmax $\left.{ }^{\circledR}\right)$, acondicionado em sacos de plástico $(13 \times 20 \mathrm{~cm})$. As sementes dos tratamentos com quinze e trinta dias de estratificação, foram semeadas em 04 e 19 de março de 2004, respectivamente. As embalagens contendo o substrato e as sementes foram mantidas em casa de vegetação com irrigação manual, conforme a necessidade. Em 19 de abril o material foi transferido ambiente externo a casa de vegetação irrigado por aspersão e coberto com sombrite (50\%) e com filme plástico de 100 micra. Em 14 de agosto de 2004 retirouse a cobertura plástica e o sombrite.

Após a semeadura iniciou-se a contagem, a cada dois dias, das plântulas que emergiram para calculo do índice de velocidade de emergência em campo (IVEC), utilizando fórmula obtida a partir do exemplo citado por Agnes (1981):

IVEC $=\frac{n_{1}}{d_{1}}+\frac{n_{2}-n_{1}}{d_{2}-d_{1}}+\frac{n_{3}-n_{2}}{d_{2}-d_{1}}+\ldots \frac{n_{n}-n_{n-1}}{d_{n}-d_{n-1}}$

onde: $\mathrm{n}_{1} ; \mathrm{n}_{2} ; \mathrm{n}_{3 ;} \ldots ; \mathrm{n}_{\mathrm{n}}$ é o número de plantas emergidas da primeira a enésima leitura e $\mathrm{d}_{1} ; \mathrm{d}_{2} ; \mathrm{d}_{3 ;} \ldots ; \mathrm{d}_{\mathrm{n}}$ é o número de dias transcorridos da semeadura até a 
enésima leitura. Entretanto, Os dados foram analisados como soma mensal e acumulada ao longo dos meses, até novembro de 2004, quando avaliou-se ainda a percentagem de plântulas emergidas e de plantas com sintoma de nanismo fisiológico, diâmetro do tronco medido a $10 \mathrm{~cm}$ acima do substrato e altura das plantas.

Os dados foram submetidos à análise da variação e discriminação de tratamentos pela comparação de médias pelo teste de Duncan $(\alpha \leq 0,05)$, utilizando-se o software WinStat (WinStat, 2000). Para a análise estatística dos dados expressos em percentagem, foi realizada a transformação segundo o Arco Seno $(\mathrm{x} / 100)^{1 / 2}$ e os dados do IVEC em $(x+0,5)^{1 / 2}$.

\section{Resultados e discussão}

Os resultados obtidos para percentual de plântulas emergidas indicam interação entre os fatores cultivar e período de estratificação. A Seleção 039.03.02 apresentou os maiores percentuais de emergência quando estratificadas por 15 e 30 dias superando o tratamento sem estratificação e a cultivar Nemaguard, naqueles dois períodos (Tabela 1 ).

Apesar das diferenças entre as cultivares, verificou-se que a estratificação proporcionou uma rápida resposta para o início da emergência, em média de oito a doze dias, para ambas as cultivares (Figura 1), porém para a Seleção 039.03-02 os

Tabela I. Percentagem média de plântulas emergidas de sementes dos porta-enxertos de pessegueiro cultivar Nemaguard e Seleção 039.03-02, em três períodos de estratificação em frio. FAEM/ UFPel, Pelotas-RS, 2004

\begin{tabular}{cccc}
\hline \multirow{2}{*}{ Porta-enxerto } & \multicolumn{3}{c}{ Estratificação (dias) } \\
\cline { 2 - 4 } Nemaguard & $\mathbf{0}$ & $\mathbf{1 5}$ & $\mathbf{3 0}$ \\
Seleção 039.03-02 & $40,0 \mathrm{aA}$ & $43,0 \mathrm{bA}$ & $50,0 \mathrm{bA}$ \\
& $48,0 \mathrm{aB}$ & $78,0 \mathrm{aA}$ & $84,0 \mathrm{aA}$ \\
\hline
\end{tabular}

Nota: Médias seguidas de mesma letra minúscula na coluna e maiúscula na linha, não diferem entre si pelo teste de Duncan a 5\% de significância.

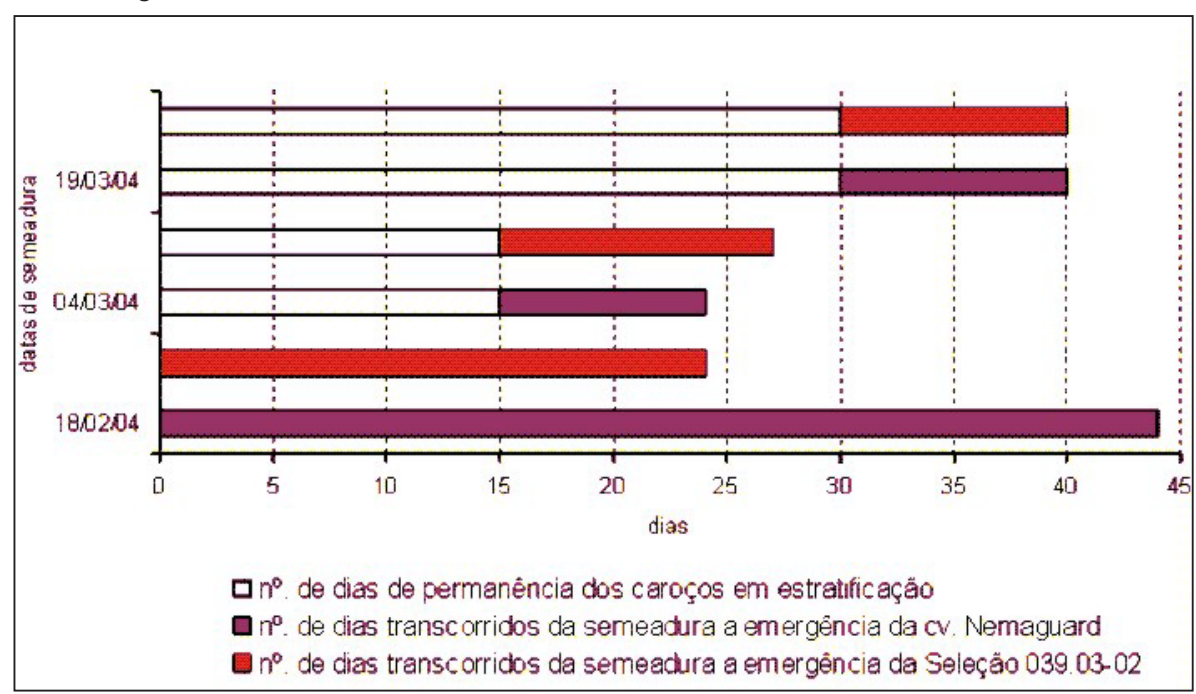

Figura I. Número de dias transcorridos desde a semeadura até o início da emergência das plântulas dos porta-enxertos de pessegueiro cultivar Nemaguard e Seleção 039.03.02, submetidos a três períodos de estratificação 
percentuais de emergência obtidos já no mês de março foram superiores a $70 \%$ (Figura 2), enquanto que na cultivar Nemaguard, no mesmo período, a chegou a 30\% (Figura 3). Mesmo não diferindo da cultivar Nemaguard na ausência de estratificação das sementes, a Seleção 039.03-02 necessitou de 24 dias para o início da emergência das plântulas, apresentando o maior percentual de plantas emergidas no mês de agosto (18\%), enquanto que na cultivar Nemaguard o início da emergência ocorreu aos 44 dias, com maior porcentagem de plântulas emersas também no mês de agosto (37\%), diferentemente da resposta observada quando se utilizou a estratificação (Figura 3). Isso provavelmente

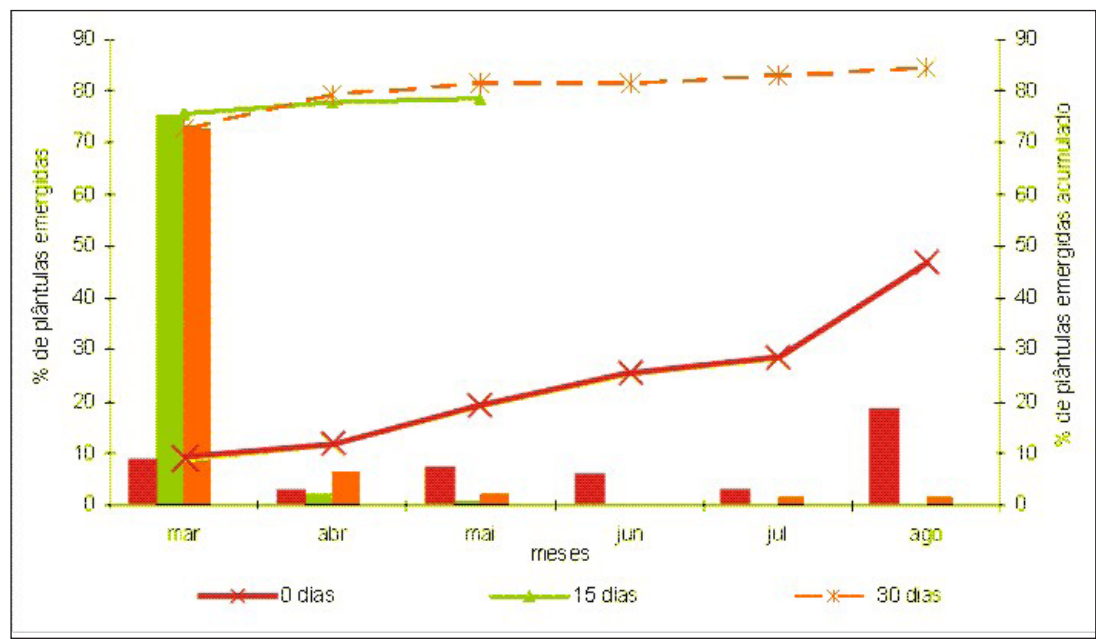

Figura 2. Percentuais mensal de plântulas emergidas (barras) e acumulado de plântulas emergidas (linhas) nos meses de março a agosto para a Seleção 039.03.02, em função de períodos de estratificação em frio ( 0,15 e 30 dias $)$

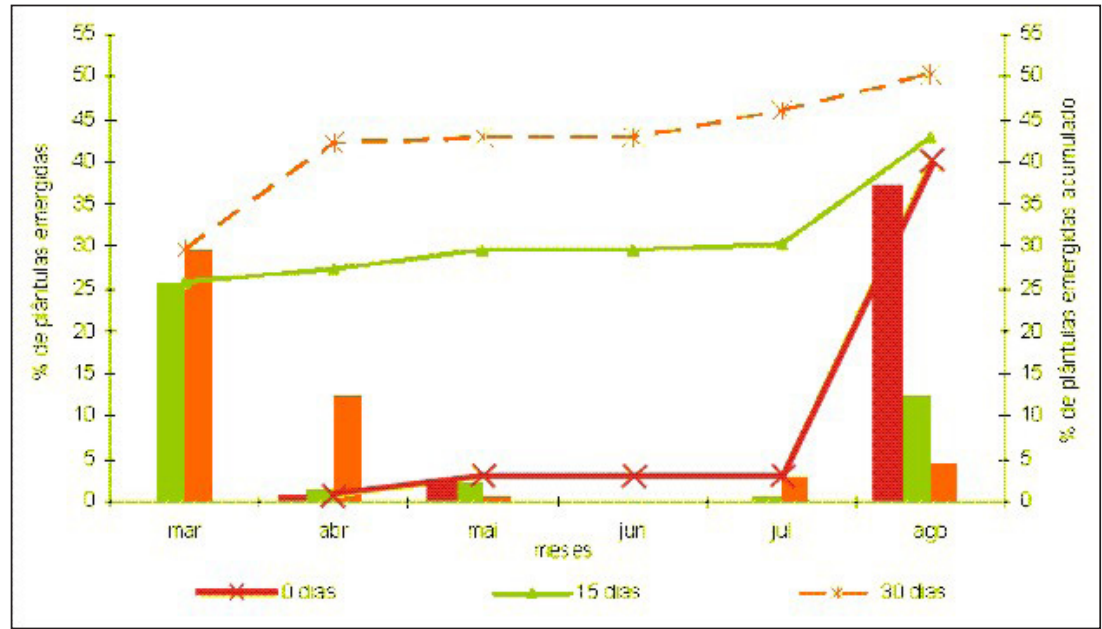

Figura 3. Percentual de plântulas emergidas de sementes (barras) e percentual acumulado de plântulas emergidas (linhas) nos meses de março a agosto para a cultivar Nemaguard em função de períodos de estratificação em frio (zero, 15 e 30 dias) 
ocorreu porque as sementes deste portaenxerto, somente no mês de agosto tiveram acúmulo de frio suficiente para promover a emergência de parte das sementes que ainda mantinham os embriões viáveis.

Essas respostas obtidas permitem inferir que Nemaguard apresenta sementes com maior grau de dormência em relação à Seleção 039.03-02, fato que possui uma relação direta com a exigência em frio das plantas de cada cultivar avaliada. De acordo com Campana et al.(1993) a estratificação em baixa temperatura influencia diretamente o metabolismo de fitohormônios, modificando os processos de dormência e germinação das sementes. Sendo assim, para a Seleção 039.03.03, devido apresentar menor exigência em frio em relação à Nemaguard, a estratificação por 15 e 30 dias foi suficiente para promover uma rápida mudança no balanço entre promotores e inibidores da germinação, permitindo obter uma taxa de emergência em torno de $75 \%$, em apenas 12 e 10 dias, respectivamente.

Avaliando o efeito da estratificação de sementes de pessegueiro cv. Campinas 1, Wagner Júnior et al. (2007) constataram que a temperatura constante de $10^{\circ} \mathrm{C}$ foi a que possibilitou obter uma concentração da germinação (cerca de 90\%), entre 25 e 27 dias após início do tratamento, enquanto que nas sementes mantidas a $5^{\circ} \mathrm{C}$ constante, e $5^{\circ} \mathrm{C}$ e $10^{\circ} \mathrm{C}$ alternados, a germinação foi de $100 \%$, porém aos 53,33 e 37 dias após o início da estratificação. Verificaram ainda que o período entre o início e o final da germinação variou entre 10 e 23 dias.

Segundo Dahal et al. (1996), a estratificação em temperaturas próximas a $0^{\circ} \mathrm{C}$ podem reduzir a taxa de respiração das sementes, retardando o início da geminação e emergência. Embora essa influência ocorra efetivamente, no presente trabalho verificouse que quando a estratificação em baixa temperatura supre a necessidade de frio da semente, estas respondem rapidamente a germinação e emergência quando colocadas em ambiente com temperatura acima de $15^{\circ} \mathrm{C}$, resultando em lotes de seedlings com crescimento mais uniforme.

Os percentuais de plântulas emergidas obtidos e o tempo decorrido entre a semeadura e a emergência, em função da estratificação em frio, para as duas cultivares avaliadas, estão de acordo com Carvalho e Nakagawa (1983), segundo os quais, os efeitos da temperatura sobre a germinação de sementes podem ser avaliados a partir de mudanças ocasionadas na percentagem, velocidade e freqüência de germinação ao longo do tempo. Dessa forma, as sementes que receberam frio artificial emergiram mais rapidamente e em maior percentual do que as sementes mantidas em temperatura ambiente, estas por sua vez tiveram que acumular frio a campo para superar a dormência e emergir, o que ocorreu em maior percentual somente no mês de agosto, principalmente para a cultivar Nemaguard (Figura 3).

A aplicação de giberelina nas sementes dos dois porta-enxertos proporcionou o aumento em cerca de $10 \%$ na porcentagem de plântulas emergidas, e de $50 \%$ no IVEC, sem diferenças, entretanto, entre as concentrações de 50 e $100 \mathrm{mg} \mathrm{L}^{-1}$ (Tabela 2). Estes resultados são similares aos obtidos por Barbosa et al. (1987), que estratificando sementes sem endocarpo do porta-enxerto de pessegueiro Okinawa, em frio durante 10 dias, e tratadas com $20 \mathrm{mg} \mathrm{L}^{-1}$ de giberelinas, obtiveram $66,0 \%$ de plântulas emergidas, enquanto que no tratamento sem giberelina a emergência foi de apenas 36,0\%. Azevedo et al. (2004) observaram que sementes 
Tabela 2. Percentagem média de plântulas emergidas, índice de velocidade de emergência em campo (IVEC), diâmetro, altura de plantas e percentual de nanismo fisiológico dos porta-enxertos de pessegueiro Nemaguard e Seleção 039.03.02, em três concentrações de giberelina

\begin{tabular}{cccc}
\hline \multirow{2}{*}{ Variáveis analisadas } & \multicolumn{3}{c}{ Giberelina $\left(\mathbf{m g ~ \mathbf { ~ L } ^ { - 1 } )}\right.$} \\
\cline { 2 - 4 } & $\mathbf{0}$ & $\mathbf{5 0}$ & $\mathbf{1 0 0}$ \\
\hline Plântulas emergidas (\%) & $51,00 \mathrm{~b}$ & $60,00 \mathrm{ab}$ & $61,00 \mathrm{a}$ \\
IVEC & $1,44 \mathrm{~b}$ & $2,17 \mathrm{a}$ & $2,20 \mathrm{a}$ \\
Diâmetro do tronco (mm) & $2,95 \mathrm{a}$ & $3,26 \mathrm{a}$ & $3,42 \mathrm{a}$ \\
Altura de plantas (cm) & $46,05 \mathrm{a}$ & $46,66 \mathrm{a}$ & $47,85 \mathrm{a}$ \\
Nanismo fisiológico (\%) & $27,66 \mathrm{a}$ & $37,72 \mathrm{a}$ & $41,16 \mathrm{a}$ \\
\hline
\end{tabular}

Nota:Médias seguidas de mesma letra minúscula na linha, não diferem entre si pelo teste de Duncan a $5 \%$ de significância.

sem endocarpo dos porta-enxertos Seleção 039.03.02 e Nemaguard, estratificadas a $1^{\circ} \mathrm{C}$ durante 60 dias, apresentaram em média $76,17 \%$ de plântulas emergidas, enquanto que nas sementes mantidas a $22^{\circ} \mathrm{C}$ a média de germinação foi de $27,20 \%$. No mesmo trabalho, verificaram que sementes não estratificadas, porém tratadas com $100 \mathrm{mg}$ $\mathrm{L}^{-1}$ de giberelina a emergência foi de $55,61 \%$, valor superior em relação ao tratamento sem giberelina e sem estratificação $(36,07 \%)$. Embora os autores não tenham registrado interação entre os fatores temperatura e doses de giberelina, é notável o efeito positivo das baixas temperaturas e do $\mathrm{AG}_{3}$ na germinação das sementes.

As sementes dos porta-enxertos, quando submetidos a 15 e 30 dias de estratificação, apresentaram maiores valores de IVEC nos meses de março e abril, enquanto que no tratamento sem frio os melhores resultados somente ocorreram em agosto (Figuras 4 e 5). Verifica-se assim, que na ausência de estratificação as sementes necessitaram, portanto,

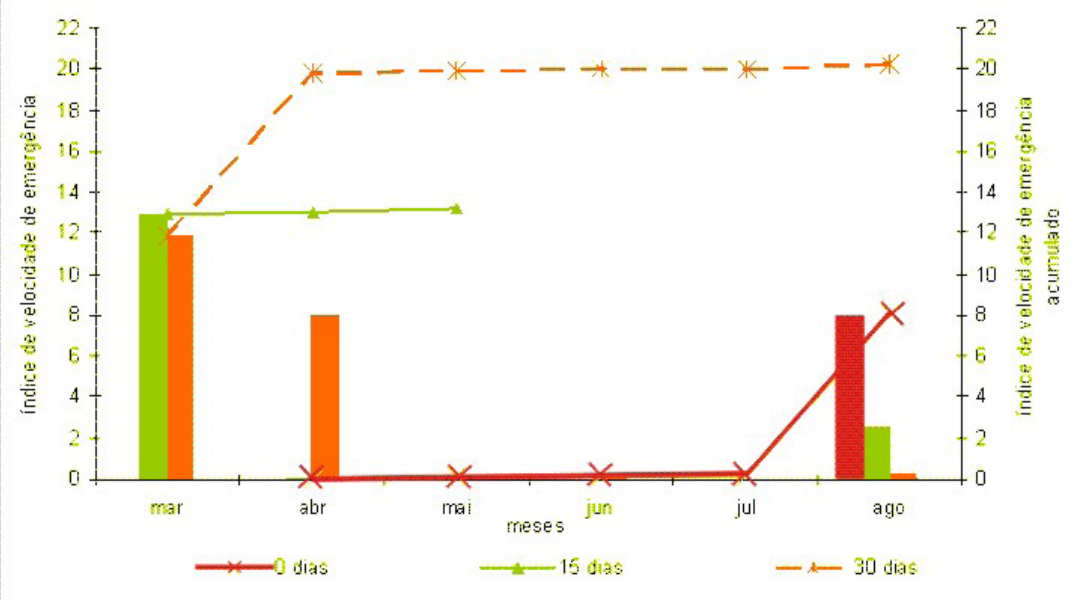

Figura 4. Índice de velocidade de emergência do porta-enxerto de pessegueiro Nemaguard nos meses e índice acumulado de março a agosto em função dos períodos de estratificação em frio de $1^{\circ} \mathrm{C}(0,15$ e 30 dias $)$ 


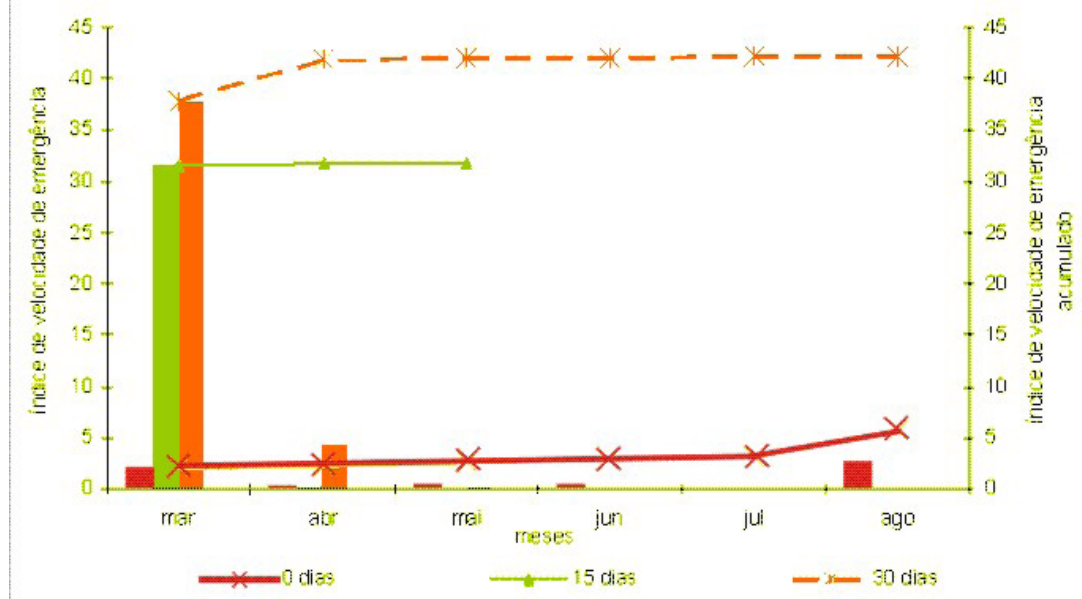

Figura 5. Índice de velocidade de emergência do porta-enxerto Seleção 039.03 .02 nos meses e índice acumulado de março a agosto em função dos períodos de estratificação em frio de $1^{\circ} \mathrm{C}(0,15$ e 30 dias $)$

de um período mais longo para superação da dormência. Estes resultados são semelhantes aos obtidos por Agnes (1981), o qual também constatou efeito positivo em relação aos tratamentos sem estratificação sobre IVEC quando sementes de cinco cultivares de pessegueiro (Aldrighi, Biuti, Campinas, Capdeboscq e Real) foram estratificadas em frio $\left(5-10^{\circ} \mathrm{C}\right)$ durante trinta dias.

Avaliando-se o efeito do fator cultivar, verificou-se a Seleção 039.03.02 obteve IVEC 100\% superior e altura de plântulas 50\% superior a cultivar Nemaguard. Em relação ao período de estratificação, a manutenção das sementes durante 30 dias em frio de $1^{\circ} \mathrm{C}$, possibilitou a obtenção de resultados superiores a zero e 15 dias para ambas variáveis (Tabela 3 ).

Apesar do efeito sobre IVEC das sementes, o crescimento em altura das duas cultivares não foi influenciado pela aplicação de giberelina (Tabela 2). Por outro lado, foi observado efeito das cultivares sobre esta variável, tendo a Seleção 039.03.02 apresentado crescimento superior a 50 $\mathrm{cm}$, o qual diferiu da cultivar Nemaguard (Tabela 3). Porém, independente da cultivar,

Tabela 3. Índice de velocidade de emergência em campo (IVEC) e altura de plantas dos portaenxertos Nemaguard e Seleção 039.03.02, em três períodos de estratificação em frio de $1{ }^{\circ} \mathrm{C}$

\begin{tabular}{ccc}
\hline Fatores & \multicolumn{2}{c}{ Variáveis } \\
\hline Porta-enxertos & IVEC & Altura de plantas $\mathbf{( c m})$ \\
Semaguard & $1,28 \mathrm{~b}$ & $38,65 \mathrm{~b}$ \\
Seleção 039.03.02 & $2,59 \mathrm{a}$ & $55,06 \mathrm{a}$ \\
\hline Períodos de estratificação (dias) & & \\
\hline 0 & $0,48 \mathrm{~b}$ & $23,43 \mathrm{c}$ \\
15 & $2,02 \mathrm{~b}$ & $54,34 \mathrm{~b}$ \\
30 & $3,30 \mathrm{a}$ & $62,79 \mathrm{a}$ \\
\hline
\end{tabular}

Nota: Médias seguidas de mesma letra minúscula na coluna, não diferem entre si pelo teste de Duncan a $5 \%$ de significância. 
maiores alturas médias de plântulas foram também obtidas com o aumento do período de estratificação, superando $60 \mathrm{~cm}$ quando as sementes foram estratificadas por trinta dias. Verificou-se com esse resultado que o padrão de crescimento foi adequado, pois o valor é similar a média de altura obtida para o porta-enxerto Capdeboscq, obtido por semeadura direta no campo (SCHUCH et al., 1999) e para as cultivares Campinas $1 \mathrm{e}$ Progênie 290, estratificados a 5 (WAGNER JÚNIOR et al. 2008).

Para o diâmetro médio do tronco das plântulas não se verificou diferença entre as cultivares quando as sementes foram semeadas sem estratificação. Entretanto, quando estratificadas, as sementes da Seleção 039.03.02 apresentaram valores em média 1,5 vezes superiores ao da cultivar Nemaguard (Tabela 4). Apesar de ambas terem respondido positivamente ao tratamento com frio, o melhor resultado da Seleção 039.03.02 para este parâmetro, pode ser também evidenciada pelo incremento um limitado crescimento até este período. No Rio Grande do Sul a enxertia do pessegueiro é realizada principalmente nos meses de novembro e dezembro, sendo assim o diâmetro do tronco dos porta-enxertos obtidos ficaram aquém do indicado por Finardi (1998) e nas Normas de Produção de Mudas (RIO GRANDE DO SUL, 1998), devendo ser de aproximadamente $6-10 \mathrm{~mm}$, na região que recebe o enxerto. Apesar disso, verificou-se que para a Seleção 039.03.02 a estratificação das sementes a $1^{\circ} \mathrm{C}$, por 30 dias, permitiu obter plântulas com diâmetro do tronco de $4,95 \mathrm{~mm}$, ou seja, muito próximo do padrão recomendado. Sendo assim, há de se considerar que se a enxertia das mesmas for realizada no mês de dezembro, possivelmente as mesmas atingiriam diâmetro dentro dos padrões desejados. Em plântulas de Campinas 1 e progênie 29, Wagner Júnior et al. (2008) obtiveram valores de diâmetro de tronco 1,4 vezes inferior ao do presente trabalho, quando as sementes foram estratificadas a $5^{\circ} \mathrm{C}$, levando a sugerir que quando a estratificação é realizada por período

Tabela 4. Diâmetro médio do tronco $(\mathrm{mm})$ dos porta-enxertos Nemaguard e Seleção 039.03 .02 em três períodos de estratificação em frio de $\mathrm{I}^{\circ} \mathrm{C}$

\begin{tabular}{cccc}
\hline \multirow{2}{*}{ Porta-enxertos } & \multicolumn{3}{c}{ Período de estratificação (dias) } \\
\cline { 2 - 4 } & $\mathbf{0}$ & $\mathbf{1 5}$ & $\mathbf{3 0}$ \\
\hline Nemaguard & $1,71 \mathrm{aB}$ & $2,86 \mathrm{bA}$ & $3,41 \mathrm{bA}$ \\
Seleção 039.03.02 & $1,97 \mathrm{aB}$ & $4,36 \mathrm{aA}$ & $4,95 \mathrm{aA}$ \\
\hline
\end{tabular}

Nota: Médias seguidas de mesma letra minúscula na coluna e maiúsculo na linha, não diferem entre si pelo teste de Duncan a 5\% de significância.

proporcionado em relação ao tratamento sem estratificação, que foi de 2,2 e 2,5 vezes maior, com 15 dias e 30 dias respectivamente.

Considerando que a avaliação do diâmetro do tronco foi realizado no mês de novembro, em todos os tratamentos verificou-se adequado mesmo em temperaturas próximas a $0^{\circ} \mathrm{C}$, no momento em que as sementes recebem temperatura ótima para germinação, o processo ocorre mais rapidamente e com maior intensidade resultando em plantas com 
maior altura e diâmetro, conforme observado no presente experimento.

A variações na altura das plantas seguiu a mesma tendência registrada para o diâmetro do tronco, apresentando as maiores médias para a Seleção 039.03.02, e nas sementes estratificadas por 30 dias, $55,06 \mathrm{~cm} \mathrm{e}$ $62,79 \mathrm{~cm}$, respectivamente. $O$ pequeno crescimento observado para a altura das plantas ocorreu provavelmente ao longo período o para a emergência de algumas plântulas, pela restrição de captação de luminosidade ocasionada pela proximidade entre as mesmas e a limitação de espaço físico para a formação de ramificações e enraizamento.

Como o objetivo do trabalho foi verificar o efeito da estratificação e da giberelina, principalmente na emergência e no IVEC, deve-se considerar que um manejo diferenciado com o cultivo em sacolas plásticas maiores, maior espaçamento entre as plântulas, controle mais adequado da nutrição das plântulas poderia resultar na produção de porta-enxertos dentro do padrão exigido pela legislação, conforme verificado por Picolloto et al. (2007b), para o porta-enxerto da cultivar Okinawa produzido em sacolas plásticas, em que o diâmetro do tronco, no mês de novembro, foi de $8,1 \mathrm{~mm}$.

Houve também resposta diferencial das cultivares em relação à ocorrência de plântulas com sintomas de nanismo fisiológico, quanto submetidas aos tratamentos de estratificação (Tabela 5). Enquanto para a cultivar Nemaguard não houve efeito algum dos tratamentos, com valor médio 33\% de plantas com sintoma de nanismo, para a Seleção 039.03.02 ocorreu drástica redução da anomalia com o aumento do período de estratificação, atingindo valores 5,4 inferiores aos mais de $60 \%$ observados na semeadura direta. Neste tratamento, os valores foram semelhantes ao obtidos por Barbosa et al. (1987), que observaram $15 \%$ de plantas com nanismo do porta-enxerto cultivar Okinawa, cujas semente foram estratificadas durante 20 dias. Ainda conforme estes autores, o nanismo também não foi influenciado por diferentes concentrações de giberelina (5, 10 e $20 \mathrm{mg} \mathrm{L}^{-1}$ ), sendo este efeito também não significativo no presente estudo (Tabela 2).

Os maiores índices de velocidade de emergência e percentuais de plântulas emergidas foram obtidos das sementes estratificadas em frio e tratadas com giberelina, porém, esses fatores individualmente ou combinados, não foram suficientes para promover um balanço hormonal adequado ao desenvolvimento das plantas, sem sintomas de nanismo fisiológico.

Tabela 5. Percentual de plântulas com sintomas de nanismo fisiológico dos porta-enxertos Nemaguard e Seleção 039.03.02 em três períodos de estratificação em frio de $1^{\circ} \mathrm{C}$

\begin{tabular}{cccc}
\hline \multirow{2}{*}{ Porta-enxertos } & \multicolumn{3}{c}{ Estratificação (dias) } \\
\cline { 2 - 4 } & $\mathbf{0}$ & $\mathbf{1 5}$ & $\mathbf{3 0}$ \\
\hline Nemaguard & $27,22 \mathrm{bA}$ & $36,77 \mathrm{aA}$ & $33,88 \mathrm{aA}$ \\
Seleção 039.03.02 & $66,77 \mathrm{aA}$ & $36,11 \mathrm{aAB}$ & $12,33 \mathrm{aB}$ \\
\hline
\end{tabular}

Nota: Médias seguidas de mesma letra minúscula na coluna e maiúscula na linha, não diferem entre si pelo teste de Duncan ao nível de significância de $5 \%$. 


\section{Conclusões}

De acordo com os resultados obtidos concluiu-se que:

A estratificação das sementes, à $1^{\circ} \mathrm{C}$, por até trinta dias, é mais efetiva para a superação da dormência da Seleção 039.03.02 em relação a cultivar Nemaguard, favorecendo ainda o crescimento das plântulas em altura e diâmetro tronco de ambos os genótipos, sem, entretanto eliminar completamente o aparecimento de plântulas com sintomas de nanismo fisiológico.

O uso de giberelina na concentração de $100 \mathrm{mg} \mathrm{L}^{-1}$ aumenta o percentual de plântulas emergidas dos dois genótipos avaliados.

\section{Referências}

AGNES, E. L. Efeitos do endocarpo e da vernalização na germinação das sementes de cultivares de pessegueiro (Prunus persica L. Batsch.). Viçosa, 1981. 123 f. Dissertação (Mestrado em Agronomia) - Universidade Federal de Viçosa, 1981.

AZEVEDO, F. Q.; AFONSO, L. B.; BIANCHI, V. J.; FACHINELLO, J. C. Efeito de temperatura e de giberelinas na germinação de sementes dos porta-enxertos de pessegueiro cultivares GF 655-2 e Nemaguard. In: CONGRESSSO BRASILEIRO DE FRUTICULTURA, 18., 2004, Florianópolis. Resumos... Florianópolis: Sociedade Brasileira de Fruticultura, 2004. 1 CD-ROM.

BARBOSA, W.; CAMPO, F. A. D.; OJIMA, M. Relação entre precocidade de maturação e desidratação das sementes de pêssego. Pesquisa Agropecuária Brasileira, Brasília, v. 19, n. 3, p. 337-339, 1986.

BARBOSA, W.; CAMPO, F. A. D.; OJIMA, M.; MARTINS, F. P.; RIGITANO, O. Emergência de plântulas do porta-enxerto de pessegueiro Okinawa; influência de períodos de estratificação e de ácido giberélico. Bragantia, Campinas, v. 46, n. 3, p. 435-441, 1987.

CARVALHO, P. R. C.; NAKAGAWA, J. Sementes: ciência, tecnologia e produção. Campinas, Fundação Cargill, 1983. p. 429.

CAMPANA, B.; CAFFARINI, P.; CALVAR, J.; et al. Quebra de dormência de sementes de pessegueiro (Prunus persica (L.) Batsch) mediante reguladores de crescimento. Revista Brasileira de Fruticultura, Jaboticabal, v. 15, n. 1, p. 171-176, 1993.

CASTRO, P. R. C.; VIEIRA, E. L. Aplicações de reguladores vegetais na agricultura tropical. Guaíba: Agropecuária, 2001. p. 132.

DAHAL, P.; KIM, N. S.; BRADFORD, K. J. Respiration and germination rates of tomato seeds at suboptimal temperatures and reduced water potential. Journal of Experimental Botany, Oxford, v. 47, n. 7, p. 941-947, 1996. 
FACHINELLO,J.C.Problemática das mudas de plantas frutíferas de caroço.In: SIMPÓSIO INTERNACIONAL DE FRUTAS DE CAROÇO - PESSEGOS, NECTARINAS E AMEIXAS, 1., 2000, Porto Alegre. Anais... Porto Alegre, 2000. p. 26-40.

FINARDI, N. L. Métodos de propagação e descrição de porta-enxertos. In: MEDEIROS, C. A. B.; RASEIRA, M. do C. B. (Ed.). A cultura do pessegueiro. Brasília: Embrapa-SPI; Pelotas: Embrapa-CPACT, 1998. p. 100-129.

PAULA, L. A. de; BIANCHI, V.J.; FACHINELLO, J. C.; GOMES, C.B. Reaction of five peach rootstocks to Meloidogyne incognita. In: INTERNATIONAL CONGRESS OF TROPICAL NEMATOLOGY, 2, 2009, Resumos... Maceió. Brasília: Embrapa, 2009. v.1, p.73.

PICOLLOTO, L.; BIANCHI, V. J. B; FACHINELLO, J. C. Ação de giberelinas e citocininas na germinação de sementes de pessegueiro. Scientia Agrária, Curitiba, v. 8, n. 3, p. 225-232, 2007a.

PICOLLOTO, L.; BIANCHI, V. J.; GAZOLLA NETO, A.; FACHINELLO, J. C. Diferentes misturas de substratos na formação de mudas de pessegueiro, em embalagens. Scientia Agrária, Curitiba, v. 8, n. 2, p. 119-125, 2007 b.

RIO GRANDE DO SUL. Secretaria da Agricultura e Abastecimento. Departamento de Produção Vegetal. Comissão Estadual de Sementes e Mudas do Estado do Rio Grande do Sul (Porto Alegre, RS). Normas e padrões de produção de mudas fruteiras para o Estado do Rio Grande do Sul. Porto Alegre, 1998. 100p.

RAMOS, J. D.; CHALFUN, N. N. J.; PASQUAL, M.; RUFINI, J. C. M. Produção de mudas de plantas frutíferas por semente. Informe Agropecuário, Belo Horizonte, v. 23, n. 216. p. 64-72, 2002.

SCHUCH, M.W.; FACHINELLO, J. C.; NACHTIGAL, J. C.; KERSTEN, E. Obtenção de porta-enxertos de pessegueiro: comparação entre repicagem e semeadura direta no viveiro. Revista Brasileira de Agrociência, Pelotas, v. 5, n. 1, p. 4-6, 1999.

SOUZA, C. M.; BIANCHI, V. J.; ALVARENGA, D. A. Produção e certificação de mudas de macieira e pereira. Informe Agropecuário, Belo Horizonte, v. 23, n. 216, p. 49-56, 2002.

TAIZ, L.; ZEIGER, E. Fisiologia Vegetal. ; tradução Eliane Romonato Santarém ... [et al.]. 4 ed. - Porto Alegre : Artmed, 2009. 848p. il.

WINSTAT. Sistema de Análise Estatística para Windows. Universidade Federal de Pelotas - UFPel. Pelotas, RS, 2000. Disponível em: <http://www.ufpel.edu.br/ amachado>. Acesso em: 30 abr. 2004. 
WAGNER JÚNIOR, A; SILVA, J. O. C.; SANTOS, C. E. M.; PIMENTEL, L. D.; BRUCKENER, C. H. Estratificação de sementes de pessegueiro CV. “campinas 1", em temperaturas constantes e alternadas. Revista Brasileira de Agrociência, Pelotas, v. 13, n.1, p. 39-42, 2007.

WAGNER JÚNIOR, A; NERES, C. R. L.; NEGREIROS, J. R.; ALEXANDRE, R. S.; DINIZ, E. R.; PIMENTEL, L.D.; MORGADO,M.A.D.; BRUKENER, C.H. Substratos no desenvolvimento inicial de quatro cultivares de pessegueiro e uma nectarina. Ciência e Agrotecnologia, Lavras, v. 32, n.4, p. 1322-1328, 2008. 